\title{
Mental health outcomes in US and UK military personnel returning from Iraq
}

Josefin Sundin, Richard K. Herrell, Charles W. Hoge, Nicola T. Fear, Amy B. Adler, Neil Greenberg, Lyndon A. Riviere, Jeffrey L. Thomas, Simon Wessely* and Paul D. Bliese*

\section{Background}

Research of military personnel who deployed to the conflicts in Iraq or Afghanistan has suggested that there are differences in mental health outcomes between UK and US military personnel.

\section{Aims}

To compare the prevalence of post-traumatic stress disorder (PTSD), hazardous alcohol consumption, aggressive behaviour and multiple physical symptoms in US and UK military personnel deployed to Iraq.

\section{Method}

Data were from one US $(n=1560)$ and one UK $(n=313)$ study of post-deployment military health of army personnel who had deployed to Iraq during 2007-2008. Analyses were stratified by high- and low-combat exposure.

\section{Results}

Significant differences in combat exposure and sociodemographics were observed between US and UK personnel; controlling for these variables accounted for the difference in prevalence of PTSD, but not in the total symptom level scores. Levels of hazardous alcohol consumption (low-combat exposure: odds ratio $(\mathrm{OR})=0.13$ $95 \% \mathrm{Cl}$ 0.07-0.21; high-combat exposure: $\mathrm{OR}=0.23,95 \% \mathrm{Cl}$
0.14-0.39) and aggression (low-combat exposure: $\mathrm{OR}=0.36$, $95 \% \mathrm{Cl}$ 0.19-0.68) were significantly lower in US compared with UK personnel. There was no difference in multiple physical symptoms.

\section{Conclusions}

Differences in self-reported combat exposures explain most of the differences in reported prevalence of PTSD. Adjusting for self-reported combat exposures and sociodemographics did not explain differences in hazardous alcohol consumption or aggression.

\section{Declaration of interest}

J.S., N.T.F., N.G. and S.W. are based at King's College London which, for the purpose of this study and other militaryrelated studies, receives funding from the UK Ministry of Defence; N.G. is employed by the UK armed forces. R.K.H., C.W.H., A.B.A., L.A.R., J.L.T. and P.D.B. are based at the Walter Reed Army Institute of Research, which is a US Department of Defense research laboratory. The views expressed here are those of the authors and do not necessarily represent the official policy or position of the US Army Medical Command or the Department of Defense.
Studies of UK and US military personnel who have deployed to the recent conflicts in Iraq or Afghanistan have suggested that there are significant differences in mental health outcomes between personnel in the two militaries. ${ }^{1-6}$ Deployment to Iraq and Afghanistan has not been associated with post-traumatic stress disorder (PTSD) or common mental disorders for the majority of UK regular personnel, although an association between deploying in a combat role and PTSD has been demonstrated. ${ }^{1}$ In contrast, US research has shown that deployment to Iraq and Afghanistan is consistently associated with higher rates of mental health problems in general and PTSD specifically. ${ }^{2,3}$ Research has also demonstrated an association between combat experiences and PTSD in the US military. ${ }^{2,7,8}$ Overall, the prevalence of screening positive for PTSD has been reported to be higher in US compared with UK military personnel with the US typically reporting ranges between 9 and $20 \%$ and the UK reporting ranges between 3 and $7 \% .^{1,4-12}$

Deployment to Iraq and Afghanistan is also associated with higher rates of alcohol misuse in UK and US personnel, but self-reported alcohol misuse tends to be greater in UK compared with US military personnel. ${ }^{1,13-16}$ The prevalence of hazardous consumption of alcohol has been reported as $67 \%$ and $49 \%$ in UK male and female personnel respectively, compared with between 8 and $36 \%$ in US military personnel using similar measures. ${ }^{17-21}$ Deployment to Iraq and Afghanistan is also associated with aggressive behaviour, and similar prevalence of

*These authors contributed jointly to the work. violent or aggressive behaviour has been reported in studies of UK (12.6\%) and US personnel (11.2-18.4\%) deployed to Iraq and Afghanistan. ${ }^{2,10,22}$

Finally, deployments are associated with increased risk for reports of post-deployment somatic complaints often comorbid with psychological health symptoms. For example, $34.4 \%$ of US soldiers scoring positive for PTSD reported a high level of somatic complaints, compared with $5.2 \%$ for those who did not score positive for PTSD, with an overall prevalence of $12.0 \% .^{3}$ Similar prevalence has been reported in the UK military (12\%), with a small association between deployments and increased risk for reports of post-deployment somatic complaints. ${ }^{5}$

A number of reasons have been proposed for the differences between US and UK forces, including differences in levels of combat exposure, length of deployment, dwell time (the amount of time that service members spend in their home nation between deployments), time from returning from deployment to survey administration, level of anonymity of reporting, proportion of National Guard/reserve personnel, and differences in alcohol use among service members. ${ }^{6,23}$ However, there have been no direct comparisons to determine the specific reasons for the differences. A recent meta-analysis suggested that the principal reason for the differences in PTSD prevalence was because the majority of US studies have focused on combat infantry units, whereas UK studies have involved random samples of the entire deployed population. $^{23}$ Support personnel account for nearly two-thirds of all deployed service members, and there is strong evidence of a dose-response effect of greater combat frequency and intensity 
on the development of PTSD. ${ }^{2,23,24}$ Although the meta-analysis provided a useful way to group the large number of prevalence studies, there has not been an effort to combine data from different study samples, which would permit controlling for variables known to be associated with mental health outcomes. In our study we therefore combine data from comparable US and UK study samples. We compare the prevalence of postdeployment health outcomes, including PTSD, hazardous alcohol consumption, aggressive behaviour and multiple physical symptoms in UK and US military personnel who were deployed to Iraq in 2007-2008. We also examine whether demographic and military characteristics or combat exposures may explain differences between the post-deployment health outcomes observed in UK and US military personnel.

\section{Method}

Data were combined from one US and one UK study that assessed post-deployment mental health in military personnel who had deployed to Iraq. ${ }^{1,25}$ The two data-sets were the only data-sets that US and UK investigators could identify, among a large number of studies, that were comparable in terms of deployment location, time period of deployment, survey items, timing of survey administration and level of confidentiality in the survey administration methods. Most US post-deployment prevalence studies have used anonymous survey methods, whereas most UK studies have required collection of personal identifiers for longitudinal tracking. Use of identifiers has been shown to influence willingness to report mental health concerns (compared with anonymous reporting). ${ }^{26,27}$ The two data-sets used in this study both involved collection of identifiers to allow linkage with other data, and were thus not anonymous.

The US data were collected as part of a larger study on postdeployment transition. ${ }^{25}$ This study was approved by an institutional review board at the Walter Reed Army Institute of Research. In 2008, surveys were administered to US soldiers in an active component brigade combat team, 4 months after their return from a 15-month combat deployment to Iraq. Surveys were administered in large classrooms on a US army base in Germany. Participation was voluntary; $90.1 \%$ of potential participants provided informed consent and took part in the study. The survey was completed by 1658 soldiers but the final sample for the current study was 1591, excluding the few who had never deployed or had not deployed with the Brigade.

The UK data were collected as part of a longitudinal cohort study of the effect of deployment to Iraq or Afghanistan. ${ }^{1}$ The study received ethics approval from the Ministry of Defence's research ethics committee and King's College Hospital local research ethics committee. The cohort started in 2004, with a further follow-up between 2007 and $2009(n=6427)$. At that time two new samples of individuals who had deployed to Afghanistan between April 2006 and April $2007(n=894)$ or who had joined the UK military since the cohort was first recruited in 2003 $(n=2663)$ were added to the cohort. It was the latter group who formed the sample frame for the current analyses (those who joined the study for the first time at the second phase of data collection and who had deployed to Iraq in 2007-2008 $(n=504)$ ), to ensure a comparable sample frame with the US study. Participants were followed up on average a year after return from deployment.

The final analysis sample was limited to regular enlisted army male personnel, resulting in a total number of 1560 US soldiers and 313 UK soldiers who had deployed to Iraq in 2007-2008. There was considerable overlap between the UK and US questionnaires and variables that had been assessed with the same measure or that were comparable were identified (measures were similar because some of the authors had participated in an international technical panel in which they discussed using comparable approaches. The panel was sponsored through the Technical and Cooperation Program). Variables that were comparable but had used different response formats in the two studies were recoded to a similar response scale.

\section{Measures}

Comparable variables included sociodemographics and military characteristics: age at questionnaire completion, level of education, rank, marital status, years in service, total number of deployments to Iraq and Afghanistan and career intentions; combat experiences included 11 items taken from the Combat Experiences Scale, ${ }^{2}$ responses were coded based on whether an experience was endorsed as having happened at least once during the deployment.

The main outcomes included the 17-item National Center for PTSD Checklist (PCL) ${ }^{28}$ to measure probable PTSD, and the 3-item Alcohol Use Disorders Identification Test - Consumption subscale (AUDIT-C) ${ }^{29}$ to examine hazardous alcohol consumption. Two definitions of probable PTSD were examined, PCL-50 defined as a total score of 50 and above, and PCL-DSM-IV based on DSM-IV criteria, ${ }^{30}$ which required that the participant scored moderate or above on one of the re-experiencing symptoms, three avoidance symptoms and two hyperarousal symptoms. ${ }^{2,28}$ In addition to examining probable PTSD, differences in PCL total score were examined with ordinary least squares (OLS) regression. This continuous PTSD outcome was used because of low levels of probable PTSD in the UK sample.

The majority of both the UK and the US samples scored above the standard cut-off of $4 / 5$ on the AUDIT-C. ${ }^{29}$ A receiver operating characteristics (ROC) analysis was carried out for the UK sample to assess the sensitivity and specificity of the AUDIT-C using the full AUDIT with a cut-off of 16 as the criterion for alcohol misuse. $^{29}$ The ROC analyses based on the total AUDIT-C scores indicated that a cut-off of 10 on the AUDIT-C resulted in the best sensitivity and specificity ( $78 \%$ and $80 \%$ respectively). The area under the curve (AUC) was 0.86 (95\% CI 0.82-0.91). Therefore, a cut-off of 10 on the AUDIT-C was used for the multivariable analyses of alcohol misuse.

Other outcomes included a list of nine physical symptoms (such as stomach pain and headaches); the US items were drawn from the PHQ-15, ${ }^{31}$ and the UK items were taken from a checklist of 53 symptoms. ${ }^{5,32}$ We used a case definition for multiple physical symptoms as two or more symptoms. Aggressive behaviour was assessed with four items that asked participants whether in the past month they 'got angry with someone and yell or shout at them', 'got angry with someone and kicked or smashed something, slammed the door, punched the wall', 'threatened someone with physical violence' or 'got into a fight with someone and hit the person. ${ }^{10}$ For examining aggressive behaviour as an outcome we used the most specific item, 'got into a fight with someone and hit the person', as evidence of aggressive behaviour. ${ }^{10}$

\section{Analyses}

All analyses were carried out in Stata 11.2 on Windows. The sociodemographic and military characteristics, combat experiences and outcome measures were compared between the UK and US samples. Proportions were calculated and statistical significance was assessed with Pearson's $\chi^{2}$ statistic. Associations between cohort (UK or US) and dichotomous health outcomes were modelled using logistic regression analyses for PTSD, hazardous 
alcohol consumption, aggressive behaviour and multiple physical symptoms. We modelled the total score of the PCL using OLS regression and present the unadjusted and adjusted mean scores by cohort. The proportion of missing values was $7.4 \%$. Complete cases analysis was used for each health outcome (PTSD outcomes $n=1747$; alcohol misuse $n=1801$; aggressive behaviour $n=1804$; multiple physical symptoms $n=1810$ ).

Analyses were stratified by combat exposure because there was a significant difference in the level of exposures between the US and the UK samples, and previous research has shown that those in combat roles and those with high levels of exposure are at greatest risk of health problems. The cut-off for the stratification variable was set at five or more combat experiences, this was the mean and median score for the US sample (the UK sample had a mean and median score of four combat exposures). The cut-off of five was chosen due to fewer cases of PTSD in the UK group with low-combat exposures when the cut-off was set at four or more experiences $(n=3)$. Results were comparable using both cut-offs with the exception for the adjusted comparison of PCL-DSM-IV with high levels of combat exposures, which became significant with a higher prevalence of PTSD in the US sample for the cut-off of four (odds ratio (OR) $=1.87,95 \%$ CI 1.07-3.29).

In the adjusted analyses of aggressive behaviour, we entered hazardous alcohol use into the model as a covariate because of differences in hazardous alcohol use between the UK and US samples and the association between hazardous alcohol use and aggressive behaviour. Level of education was not included in the adjusted analyses due to a high association with rank (rho $(\rho)=0.66)$.

\section{Results}

Compared with the UK sample, the US sample was older (although the majority of both samples were under 30 years of age), less likely to hold a degree, less likely to be married or in a long-term relationship (the response option being in long term relationship' was included in the UK, but not the US, questionnaire), less likely to be an officer and more likely to have served for less than 5 years or 13 or more years in the military, the UK sample was more likely to have served for 5-12 years (Table 1 ). The UK sample was also more likely to have deployed to Iraq and Afghanistan three or more times and to report having career intentions of staying in the military. Stratifying for level of combat exposure reversed the association between cohort and number of deployments to Iraq and Afghanistan in the high-combat exposure group, with the US sample more likely to have deployed twice. All other differences between the UK and US samples remained significant after stratifying for level of combat exposure (Table 2).

The US sample reported more combat exposures overall and were significantly more likely to report handling human remains, being in a threatening situation where they were unable to respond, directing fire at the enemy, clearing/searching buildings and encountering sniper fire than the UK sample (Table 3). In contrast, the UK sample was more likely to report indirect fire (artillery, mortar or rocket fire).

Comparison of unadjusted proportions of post-deployment health outcomes showed that the US sample had a higher prevalence of probable PTSD, based on the PCL-50 definition in the high-combat exposure group and a higher prevalence of PTSD based on the PCL-DSM-IV definition in both the lowand high-combat exposure groups (Table 4). The prevalence of hazardous alcohol use was higher in the UK compared with the US sample in both the low- and high-combat exposure groups (Table 5). There was a marked difference between the UK (52\%) and US (17\%) samples who reported drinking ten or more drinks/units on a typical day of drinking. There were differences between the UK and the US samples in aggressive behaviours, and among the low-combat exposure groups, the UK sample

\begin{tabular}{|c|c|c|c|c|}
\hline & \multirow[b]{2}{*}{ UK $(n=313)$} & \multirow[b]{2}{*}{ USA $(n=1560)$} & \multicolumn{2}{|c|}{ UK V. USA } \\
\hline & & & $\chi^{2}$ (d.f.) & $P$ \\
\hline \multicolumn{5}{|l|}{ Age at assessment, years: $n(\%)$} \\
\hline $18-24$ & $166(53.0)$ & $772(49.5)$ & $17.1(2)$ & $<0.001$ \\
\hline $25-29$ & $106(33.9)$ & $425(27.3)$ & & \\
\hline 30 or older & $41(13.1)$ & $362(23.2)$ & & \\
\hline \multicolumn{5}{|l|}{ Level of education, $n$ (\%) } \\
\hline High school or equivalency/GCSES & $177(57.3)$ & $872(57.3)$ & $20.3(2)$ & $<0.001$ \\
\hline Some college or associate/A-levels & $86(27.8)$ & $537(35.3)$ & & \\
\hline Degree & $46(14.9)$ & $114(7.5)$ & & \\
\hline \multicolumn{5}{|l|}{ Marital status, $n(\%)$} \\
\hline Married/in long-term relationship ${ }^{b}$ & $209(67.0)$ & $751(49.0)$ & $33.8(1)$ & $<0.001$ \\
\hline Single/widowed/divorced & $103(33.0)$ & $783(51.0)$ & & \\
\hline \multicolumn{5}{|l|}{ Rank, $n$ (\%) } \\
\hline Junior enlisted & $147(47.0)$ & $911(58.6)$ & $35.8(2)$ & $<0.001$ \\
\hline Non-commissioned officer & $121(38.7)$ & $558(35.9)$ & & \\
\hline Officer & $45(14.4)$ & $86(5.5)$ & & \\
\hline \multicolumn{5}{|l|}{ Years in service } \\
\hline Median (IQR) & $5(4-6)$ & $3(2-7)$ & $4.5^{\mathrm{C}}$ & $<0.001$ \\
\hline Up to 4 years, $n(\%)$ & $126(43.6)$ & $887(57.3)$ & $45.7(2)$ & $<0.001$ \\
\hline $5-12$ years, $n(\%)$ & $154(53.3)$ & $518(33.4)$ & & \\
\hline 13 or more years, $n(\%)$ & $9(3.1)$ & $144(9.3)$ & & \\
\hline \multicolumn{5}{|l|}{ Deployments to Iraq and Afghanistan, $n(\%)$} \\
\hline One & $208(66.5)$ & $982(63.0)$ & $23.6(2)$ & $<0.001$ \\
\hline Two & $77(24.6)$ & $522(33.5)$ & & \\
\hline Three or more & $28(9.0)$ & $56(3.6)$ & & \\
\hline Career intentions staying in service, $n(\%)$ & $165(55.2)$ & $503(32.9)$ & $53.7(1)$ & $<0.001$ \\
\hline
\end{tabular}




\begin{tabular}{|c|c|c|c|c|c|c|c|c|}
\hline & \multicolumn{4}{|c|}{ Low-combat exposure } & \multicolumn{4}{|c|}{ High-combat exposure } \\
\hline & \multirow{2}{*}{$\frac{\text { UK }(n=181)}{n(\%)}$} & \multirow{2}{*}{$\begin{array}{c}\text { USA }(n=694) \\
n(\%)\end{array}$} & \multicolumn{2}{|c|}{ UK V. USA } & \multirow{2}{*}{$\frac{\text { UK }(n=132)}{n(\%)}$} & \multirow{2}{*}{$\begin{array}{c}\text { USA }(n=866) \\
n(\%)\end{array}$} & \multicolumn{2}{|c|}{ UK V. USA } \\
\hline & & & $\chi^{2}$ (d.f.) & $P$ & & & $\chi^{2}$ (d.f.) & $P$ \\
\hline \multicolumn{9}{|l|}{ Age at questionnaire completion (years) } \\
\hline $18-24$ & $88(48.6)$ & $309(44.5)$ & $9.1(2)$ & 0.010 & $78(59.1)$ & $463(53.5)$ & $10.7(2)$ & 0.005 \\
\hline $25-29$ & $63(34.8)$ & $196(28.2)$ & & & $43(32.6)$ & $229(26.5)$ & & \\
\hline 30 or older & $30(16.6)$ & $189(27.2)$ & & & $11(8.3)$ & $173(20.0)$ & & \\
\hline \multicolumn{9}{|l|}{ Level of education } \\
\hline High school or equivalency/GCSES & $95(53.4)$ & $360(52.9)$ & $14.0(2)$ & 0.001 & $82(62.6)$ & $512(60.8)$ & $8.2(3)$ & 0.017 \\
\hline Some college or associate/A-levels & $56(31.5)$ & $274(40.2)$ & & & $30(22.9)$ & $263(31.2)$ & & \\
\hline Degree & $27(15.2)$ & $47(6.9)$ & & & $19(14.5)$ & $67(8.0)$ & & \\
\hline \multicolumn{9}{|l|}{ Marital status } \\
\hline Married/in long-term relationship ${ }^{b}$ & $117(65.0)$ & $351(51.4)$ & $10.6(1)$ & 0.001 & $92(69.7)$ & $400(47.0)$ & $23.5(1)$ & $<0.001$ \\
\hline Single/widowed/divorced & $63(35.0)$ & $332(48.6)$ & & & $40(30.3)$ & $451(53.0)$ & & \\
\hline \multicolumn{9}{|l|}{ Rank } \\
\hline Junior enlisted & $74(40.9)$ & 407 (58.9) & $30.6(2)$ & $<0.001$ & $73(55.3)$ & $504(58.3)$ & $10.8(2)$ & 0.005 \\
\hline Non-commissioned officer & $80(44.2)$ & $245(35.5)$ & & & $41(31.1)$ & $309(35.8)$ & & \\
\hline Officer & $27(14.9)$ & $39(5.6)$ & & & $18(13.6)$ & $51(5.9)$ & & \\
\hline \multicolumn{9}{|l|}{ Years in service } \\
\hline Up to 4 & $74(43.5)$ & $371(53.9)$ & $20.8(2)$ & $<0.001$ & $52(43.7)$ & $516(59.9)$ & $26.3(2)$ & $<0.001$ \\
\hline $5-12$ & $88(51.8)$ & $235(34.2)$ & & & $66(55.5)$ & $283(32.9)$ & & \\
\hline 13 or more & $8(4.7)$ & $82(11.9)$ & & & $1(0.84)$ & $62(7.2)$ & & \\
\hline \multicolumn{9}{|l|}{ Deployments to Iraq and Afghanistan } \\
\hline One & $107(59.1)$ & $424(61.1)$ & $18.2(2)$ & $<0.001$ & $101(76.5)$ & $558(64.4)$ & $7.7(2)$ & 0.021 \\
\hline Two & $49(27.1)$ & 235 (33.9) & & & $28(21.2)$ & $287(33.1)$ & & \\
\hline Three or more & $25(13.8)$ & $35(5.0)$ & & & $3(2.3)$ & $21(2.4)$ & & \\
\hline Career intentions staying in service & $109(62.6)$ & $247(36.4)$ & $32.3(1)$ & $<0.001$ & $56(44.8)$ & $256(30.1)$ & $10.9(1)$ & 0.001 \\
\hline
\end{tabular}

was more likely to report having threatened someone with violence or having had a fight and hitting a person (Table 5). Among the high-combat exposure groups the US sample was more likely to report yelling or shouting at someone, but other aggressive behaviours were comparable. There was no difference between the UK and US samples in multiple physical symptoms in either the low- or high-combat exposure groups (online Table DS1).

The stratified analyses of health outcomes by high- and lowlevels of combat exposure suggested that there were interaction effects between sample and combat exposure. There was a small but significant interaction term for sample and combat exposure for the OLS regression of PCL total score (regression coefficient $0.83,95 \%$ CI $0.74-0.91$ ) but the interaction term did not reach statistical significance for any other outcome (PCL-50: $\mathrm{OR}=1.06,95 \%$ CI 0.90-1.25; PCL-DSM-IV: OR $=0.99,95 \%$ CI $0.35-2.75$; hazardous alcohol misuse: $\mathrm{OR}=1.09$, 95\% CI 0.99 1.19; aggressive behaviour: $\mathrm{OR}=1.09,95 \%$ CI $0.98-1.21$; physical symptoms: $\mathrm{OR}=1.05,95 \%$ CI $0.94-1.18$ ).

Adjustment for combat exposures appeared to account for the difference between the UK and US samples in prevalence of probable PTSD based on both the PCL-50 definition and PCL-DSM-IV. However, the confidence intervals for the comparisons on the PCL-DSM-IV definition only just included one, suggesting that a real difference might still be present (Table 6). There was a significant difference between the UK and US samples in the average PCL total score, with the US sample

\begin{tabular}{|c|c|c|c|c|}
\hline & \multirow[b]{2}{*}{ UK $(n=313), n(\%)$} & \multirow[b]{2}{*}{ USA $(n=1560), n(\%)$} & \multicolumn{2}{|c|}{ UK V. USA } \\
\hline & & & $\chi^{2}$ (d.f.) & $P$ \\
\hline \multicolumn{5}{|l|}{ Type of exposure } \\
\hline Small arms fire & $191(64.1)$ & $1054(69.6)$ & $3.5(1)$ & 0.06 \\
\hline Handled human remains & $44(14.8)$ & $646(42.9)$ & $82.7(1)$ & $<0.001$ \\
\hline Dead/injured friendly forces & $177(59.2)$ & $960(62.2)$ & $0.9(1)$ & 0.332 \\
\hline Hostility from civilians & $168(56.6)$ & 787 (51.0) & $3.1(1)$ & 0.077 \\
\hline Threatening situation unable to respond & $88(29.4)$ & $691(44.8)$ & $24.2(1)$ & $<0.001$ \\
\hline Directing fire at enemy & $67(22.6)$ & $753(48.8)$ & $68.7(1)$ & $<0.001$ \\
\hline Clearing/searching buildings & $110(36.7)$ & $778(50.3)$ & $18.6(1)$ & $<0.001$ \\
\hline Artillery/rocket/mortar fire & $301(98.7)$ & 1319 (85.3) & $41.9(1)$ & $<0.001$ \\
\hline Mate/buddy near you injured & 71 (23.9) & $375(24.3)$ & $0.0(1)$ & 0.884 \\
\hline Sniper fire & $91(30.6)$ & 661 (42.9) & $14.6(1)$ & $<0.001$ \\
\hline Aid to wounded & $74(24.8)$ & $439(28.4)$ & $1.7(1)$ & 0.193 \\
\hline Exposure frequency (sum of exposure types), ${ }_{1}^{b}$ median (IQR) & $4(2-6)$ & $5(2-9)$ & $-4.2^{c}$ & $<0.001$ \\
\hline
\end{tabular}


Table 4 Probable post-traumatic stress disorder (PTSD), stratified by low- and high-combat exposure

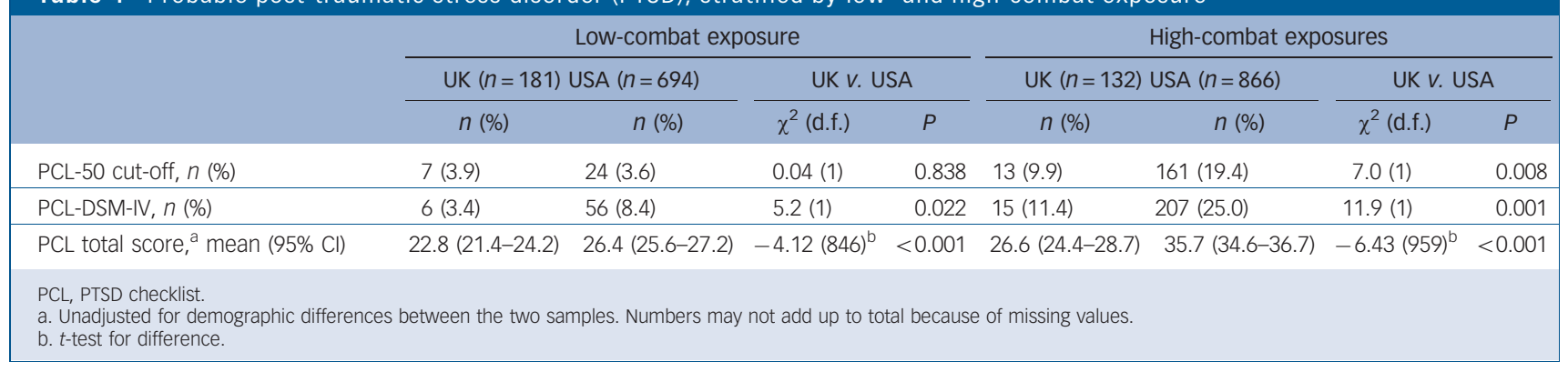

Table 5 Hazardous drinking and aggression outcomes, stratified by low- and high-combat exposure ${ }^{a}$

\begin{tabular}{|c|c|c|c|c|c|c|c|c|}
\hline & \multicolumn{4}{|c|}{ Low-combat exposure } & \multicolumn{4}{|c|}{ High-combat exposure } \\
\hline & \multicolumn{2}{|c|}{ UK $(n=181)$ USA $(n=694)$} & \multicolumn{2}{|c|}{ UK V. USA } & \multicolumn{2}{|c|}{ UK $(n=132)$ USA $(n=866)$} & \multicolumn{2}{|c|}{ UK V. USA } \\
\hline & $n(\%)$ & $n(\%)$ & $\chi^{2}$ (d.f.) & $P$ & $n(\%)$ & $n(\%)$ & $\chi^{2}$ (d.f.) & $P$ \\
\hline \multicolumn{9}{|l|}{ How often have drink of alcohol? } \\
\hline Never & $11(6.2)$ & $86(12.5)$ & $16.6(4)$ & 0.002 & $12(9.3)$ & $69(8.0)$ & $6.0(4)$ & 0.199 \\
\hline Monthly & $23(12.9)$ & $90(13.1)$ & & & $14(10.9)$ & $107(12.4)$ & & \\
\hline $2-4$ times a month & $42(23.6)$ & $226(32.8)$ & & & $34(26.4)$ & $238(27.7)$ & & \\
\hline 2-3 times a week & $72(40.5)$ & $203(29.5)$ & & & $51(39.5)$ & $265(30.8)$ & & \\
\hline 4 or more times a week & $30(16.9)$ & $84(12.2)$ & & & $18(14.0)$ & $181(21.1)$ & & \\
\hline \multicolumn{9}{|l|}{$\begin{array}{l}\text { How many drinks/units on typical day } \\
\text { of drinking? }\end{array}$} \\
\hline 1 or 2 & $25(14.1)$ & 279 (40.4) & $130.4(4)$ & $<0.001$ & $23(18.0)$ & $258(30.2)$ & $83.8(4)$ & $<0.001$ \\
\hline 2 to 4 & $26(14.7)$ & $143(20.7)$ & & & $8(6.3)$ & $186(21.8)$ & & \\
\hline 5 or 6 & $23(13.0)$ & $121(17.5)$ & & & $15(11.7)$ & 149 (17.4) & & \\
\hline 7 to 9 & $24(13.6)$ & 77 (11.2) & & & $16(12.5)$ & $117(13.7)$ & & \\
\hline 10 or more & $79(44.6)$ & $70(10.1)$ & & & $66(51.6)$ & $145(17.0)$ & & \\
\hline \multicolumn{9}{|l|}{$\begin{array}{l}\text { How often have six or more drinks/units } \\
\text { on one occasion? }\end{array}$} \\
\hline Never & $20(11.3)$ & $174(25.3)$ & $53.8(4)$ & $<0.001$ & $17(13.2)$ & $157(18.3)$ & $12.9(4)$ & 0.012 \\
\hline Less than monthly & $28(15.8)$ & $198(28.8)$ & & & $22(17.1)$ & $209(24.4)$ & & \\
\hline Monthly & $39(22.0)$ & $142(20.6)$ & & & $34(26.4)$ & $184(21.5)$ & & \\
\hline Weekly & $81(45.8)$ & $164(23.8)$ & & & $44(34.1)$ & $274(32.0)$ & & \\
\hline Daily/almost daily & $9(5.1)$ & $10(1.5)$ & & & $12(9.3)$ & $33(3.9)$ & & \\
\hline AUDIT-C 4/5 cut-off & $153(86.0)$ & $461(66.8)$ & $25.1(1)$ & $<0.001$ & $111(86.1)$ & $641(74.5)$ & $8.2(1)$ & 0.004 \\
\hline AUDIT-C 10 cut-off & $61(34.3)$ & $58(8.4)$ & $80.0(1)$ & $<0.001$ & $43(33.3)$ & $141(16.4)$ & $21.3(1)$ & $<0.001$ \\
\hline \multicolumn{9}{|l|}{ Anger } \\
\hline Angry at someone, yell or shout & $128(71.5)$ & $459(66.5)$ & $1.6(1)$ & 0.204 & 97 (73.5) & 701 (81.3) & $4.4(1)$ & 0.035 \\
\hline Angry at someone, kick, smash, punch wall & $52(29.1)$ & $179(25.9)$ & $0.7(1)$ & 0.396 & $49(37.1)$ & $353(40.9)$ & $0.7(1)$ & 0.409 \\
\hline Threaten someone with physical violence & $48(27.0)$ & 119 (17.3) & 8.5 (1) & 0.003 & 50 (37.9) & $272(31.6)$ & 2.1 (1) & 0.151 \\
\hline Fight with someone and hit the person & $31(17.3)$ & $53(7.7)$ & $15.2(1)$ & $<0.001$ & $25(18.9)$ & $152(17.6)$ & $0.1(1)$ & 0.715 \\
\hline
\end{tabular}

reporting greater mean scores in both the high- (UK adjusted mean: 26.9, 95\% CI 26.1-27.8, US adjusted mean: 35.5, 95\% CI $35.2-35.8$ ) and low-combat exposure groups (UK adjusted mean: 22.9, 95\% CI 22.4-23.4; US adjusted mean: 26.3 , 95\% CI 26.126.6); this difference remained significant after full adjustment. Combat exposure was the strongest independent predictor of PCL total score in all models, as measured by the standardised beta coefficients (data not shown). Officer rank was found to be a protective factor for the three PTSD outcomes in the high-combat exposure group (data not shown but available from the authors on request).

The UK sample reported a significantly higher prevalence of hazardous alcohol use than the US sample, in both the low- and high-combat exposure groups, that remained significant after adjusting for combat exposures and sociodemographic and military characteristics.

The UK sample reported a higher prevalence of aggressive behaviour in the low-combat exposure group. This remained significant after adjustment for hazardous alcohol consumption, combat exposures and sociodemographics and military characteristics. There was no difference between the UK and US samples in aggressive behaviour in the high-combat exposure group. Hazardous alcohol consumption was also associated with aggressive behaviour, and combat exposure was associated with aggressive behaviour in the high-combat but not in the low-combat exposure group.

There was no difference between the UK and the US sample in multiple physical symptoms. Combat exposure was associated with multiple physical symptoms in the high-combat but not in the low-combat exposure group.

\section{Discussion}

\section{Main findings}

This is the first study to combine post-deployment survey data from independent studies of US and UK military personnel who deployed to Iraq. Differences in the level of combat exposure 


\begin{tabular}{|c|c|c|c|c|}
\hline \multirow[b]{2}{*}{ Health outcome } & \multicolumn{2}{|c|}{ Low-combat exposure } & \multicolumn{2}{|c|}{ High-combat exposure } \\
\hline & OR $(95 \% \mathrm{Cl})$ & Adjusted OR $(95 \% \mathrm{Cl})$ & OR $(95 \% \mathrm{Cl})$ & Adjusted OR $(95 \% \mathrm{Cl})$ \\
\hline \multicolumn{5}{|l|}{ PCL-50 } \\
\hline Cohort (UK is reference) & $0.87(0.37-2.07)$ & $0.89(0.36-2.23)$ & $2.08(1.11-3.87)$ & $1.52(0.78-2.99)$ \\
\hline Combat exposure frequency (sum of exposure types) & $1.61(1.19-2.16)$ & $1.60(1.18-2.17)$ & $1.31(1.20-1.44)$ & $1.31(1.19-1.44)$ \\
\hline \multicolumn{5}{|l|}{ PCL-DSM-IV } \\
\hline Cohort (UK is reference) & $2.33(0.98-5.52)$ & $2.37(0.96-5.85)$ & $2.39(1.34-4.28)$ & $1.77(0.95-3.31)$ \\
\hline Combat exposure frequency (sum of exposure types) & $1.41(1.14-1.75)$ & $1.46(1.18-1.82)$ & $1.29(1.18-1.40)$ & $1.26(1.16-1.38)$ \\
\hline \multicolumn{5}{|l|}{ PCL total score } \\
\hline Cohort (UK is reference) & $3.60(1.89-5.32)^{b}$ & $3.69(1.87-5.50)^{\mathrm{b}}$ & $9.07(6.31-11.84)^{b}$ & $6.79(3.81-9.77)^{\mathrm{b}}$ \\
\hline Combat exposure frequency (sum of exposure types) & $1.77(1.24-2.31)^{\mathrm{b}}$ & $2.08(1.54-2.62)^{\mathrm{b}}$ & $2.02(1.55-2.49)^{\mathrm{b}}$ & $1.82(1.35-2.29)^{\mathrm{b}}$ \\
\hline \multicolumn{5}{|l|}{ AUDIT-C 10} \\
\hline Cohort (UK is reference) & $0.17(0.11-0.26)$ & $0.13(0.07-0.21)$ & $0.38(0.25-0.59)$ & $0.23(0.14-0.39)$ \\
\hline Combat exposure frequency (sum of exposure types) & $1.08(0.93-1.26)$ & $1.01(0.85-1.20)$ & $1.11(1.02-1.21)$ & $1.13(1.03-1.24)$ \\
\hline \multicolumn{5}{|l|}{ Aggressive behaviour } \\
\hline Cohort (UK is reference) & $0.36(0.22-0.58)$ & $0.36(0.19-0.68)$ & $0.85(0.52-1.39)$ & $0.73(0.41-1.29)$ \\
\hline Alcohol misuse & $5.33(3.23-8.79)$ & $3.60(2.07-6.28)$ & $2.82(1.94-4.11)$ & $1.94(1.30-2.89)$ \\
\hline Combat exposure frequency (sum of exposure types) & $1.15(0.96-1.37)$ & $1.13(0.93-1.38)$ & $1.18(1.08-1.28)$ & $1.16(1.06-1.27)$ \\
\hline \multicolumn{5}{|l|}{ Multiple physical symptoms } \\
\hline Cohort (UK is reference) & $0.73(0.44-1.21)$ & $0.67(0.38-1.16)$ & $1.17(0.72-1.92)$ & $0.91(0.53-1.56)$ \\
\hline Combat exposure frequency (sum of exposure types) & $1.13(0.96-1.34)$ & $1.11(0.94-1.32)$ & $1.14(1.05-1.23)$ & $1.14(1.05-1.24)$ \\
\hline
\end{tabular}

explain most of the differences in reported prevalence of PTSD, although a cohort effect in PCL total score remained significant independent of combat exposure, with the US sample reporting a greater PCL score. Although the prevalence of hazardous alcohol use was high in both US and UK participants, cohort differences in hazardous alcohol use and aggression remained significant after controlling for combat exposure and demographic variables, with the UK reporting higher levels of alcohol misuse.

\section{PTSD}

Previous research on PTSD in personnel deployed to Iraq or Afghanistan has suggested that prevalence is greater in US military personnel than in UK personnel. ${ }^{6}$ The prevalence of PTSD in UK studies of Iraq and Afghanistan deployed personnel have been reported to range between 3 and 7\%, whereas US studies have reported higher prevalence, typically between 9 and $20 \% .^{33,34}$ However, these studies did not compare prevalence directly after controlling for combat exposure or sociodemographic variables known to be associated with PTSD. The findings presented in this study are consistent with a recent meta-analysis that showed comparable results when studies involving combat infantry units were grouped separately from population-level studies involving both infantry and support units. ${ }^{23}$

\section{Hazardous alcohol use}

Hazardous alcohol use is a concern for the armed forces in both the USA and UK, and research has shown that alcohol misuse in the US military has increased over the past decade, from 15\% in $1988-1998$ to $20 \%$ in $1998-2008 .{ }^{35}$ Studies have also found that deployment to Iraq and Afghanistan is associated with increased risk of hazardous alcohol use for both UK and US personnel. ${ }^{1,2,14,36}$ The high prevalence of alcohol misuse found in this study is in line with previous research. Studies from the USA have generally reported lower prevalence and studies that have used the AUDIT-C report prevalence between 22 and $41 \% .^{36-38}$ Thus, our finding of a higher prevalence of hazardous alcohol use among UK military is supported by previous research, although this is the first study to directly compare the prevalence in UK and US military personnel deployed to Iraq. Research has also shown that alcohol misuse is more prevalent in the armed forces compared with the UK and US general population, although this is not a universal finding. ${ }^{17,39,40}$ The higher prevalence of alcohol misuse in UK personnel may be partly explained by the differences in the approach to management of alcohol misuse in the two militaries. In the US, tolerance for alcohol-related incidents in military personnel has decreased over the years, and there is both active screening for alcohol-related problems on post-deployment surveys and a military-wide campaign to reduce alcohol-related behaviours. Any alcohol-related incident, such as driving or showing up at work under the influence, is grounds for immediate commander-directed counselling and potentially separation from service if the service member does not comply with treatment. Likewise, in the UK armed forces, 'excessive' consumption of alcohol is not tolerated and is considered incompatible with military service and serious misuse of alcohol may ultimately result in discharge from the service. However, there is no formal command-directed alcohol treatment programme and the UK armed forces are more likely to argue that moderate use of alcohol may be associated with some benefits, such as encouraging unit cohesion. $^{14}$ It is possible that differences in prevalence of hazardous alcohol use reflect different cultural attitudes towards reporting of alcohol use.

\section{Aggressive behaviour}

The difference in aggressive behaviour between UK and US personnel who reported low levels of combat exposures might be expected with the higher prevalence of hazardous alcohol use among the UK military. However, although hazardous alcohol use was associated with more aggressive behaviour, adjustment for hazardous alcohol use did not remove the association for more aggressive behaviour among the UK military. Our finding that there was no difference in aggressive behaviour between UK and US personnel who reported higher levels of combat exposures is 
likely to reflect the well-established link between high combat exposure and post-deployment aggression. ${ }^{22,41}$

\section{Limitations}

The principal limitation of this study is the reliance on self-report survey data and research has shown that combat exposure reports may be biased by PTSD symptom severity. ${ }^{42-44}$ The studies used standardised validated measures to assess key health outcomes, including the PCL and the AUDIT-C, and used comparable questions on physical symptoms and aggressive behaviour. The study included active component military personnel deployed to the same country during a similar time frame, and used similar methods of non-anonymous confidential reporting, to further enhance comparability. The strict requirement to select comparable samples reduced sample size and thereby statistical power; nonetheless, the final sample of over 1800 respondents is reasonably powered to detect meaningful differences. Furthermore, the findings were comparable with those of a recent meta-analysis. ${ }^{23}$ However, because of the small UK sample within this study and the low prevalence of PTSD in this population, it is possible that the study lacked power to detect a modest difference in PTSD prevalence. There was some indication of a higher adjusted prevalence of probable PTSD among the US military, based on the PCL with a DSM-IV definition, although this did not reach statistical significance. In contrast, the difference in PCL total score remained significant after adjusting for combat exposures and sociodemographics and military factors.

Another limitation of this study is the measure of combat exposures, and although we were able to adjust for a range of combat exposures on deployment we were not able to assess the severity or frequency of exposures. The samples included in this study were solely active duty personnel with recent deployments to Iraq. We were not able to adjust for the time from return from deployment to assessment and have therefore not considered time trends, such as the increase in rates of mental health problems that takes place in the months after deployment in US personnel, but seems to be less marked in UK personnel. Using a similar comparative strategy but in different sample frames might be a useful way of studying these apparent differences in a future study. We were also not able to examine childhood adversity, which is an important predictive factor that has consistently been shown to be associated with mental health problems. Nonetheless, we were able to take account of several covariates including combat experiences and a range of sociodemographic and military characteristics and adjustment for these accounted for differences in prevalence of PTSD.

Deployment to Iraq is associated with mental health problems among military personnel; including risk of PTSD, hazardous alcohol use and aggressive behaviour. ${ }^{1,10,45-47}$ Although unadjusted prevalence of PTSD tends to be higher among US military compared with UK military, adjusting for covariates may explain this difference. In particular, the high level of combat exposures reported in the US military accounted for most of the difference in prevalence of probable PTSD. We also found that prevalence of hazardous alcohol use differs between UK and US military, with higher prevalence among the UK military. In contrast to the difference in probable PTSD, adjusting for combat experiences and sociodemographic differences did not account for the disparate prevalence of hazardous alcohol consumption.

\section{Implications}

Overall, the results demonstrate that there are similarities as well as differences between the UK and US armed forces both in terms of deployment-related health outcomes and the risk factors associated with these outcomes. Recent US trials have demonstrated that post-deployment mental health training can reduce these negative outcomes and a UK training programme based on the US training model also found positive effects, although only for hazardous alcohol use. ${ }^{12,48,49}$ This shows that post-deployment mental health training can successfully target the key mental health problems associated with deployment in both nations. Such results underscore the feasibility of brief interventions to reduce the negative impact of deployment, and combat experiences in particular, on subsequent mental health adjustment, and suggest lessons learned from the UK and US are relevant to both nations. Josefin Sundin, PhD, King's College London, Academic Centre for Defence Mental
Health (ACDMH), London, UK; Richard K. Herrell, PhD, Charles W. Hoge, MD,
Center for Military Psychiatry and Neuroscience, Walter Reed Army Institute of
Research, US Army Medical Research and Materiel Command, Silver Spring,
Maryland, USA; Nicola T. Fear, DPhil(Oxon), King's College London, King's Centre for
Military Health Research (KCMHR), London, UK; Amy B. Adler, PhD, US Army Medical
Research Unit-Europe, Walter Reed Army Institute of Research, US Army Medical
Research and Materiel Command, Heidelberg, Germany; Neil Greenberg, MD, King's
College London, Academic Centre for Defence Mental Health (ACDMH), London, UK;
Lyndon A. Riviere, PhD, Jeffrey L. Thomas, PhD, Center for Military Psychiatry and
Neuroscience, Walter Reed Army Institute of Research, US Army Medical Research
and Materiel Command, Silver Spring, Maryland, USA; Simon Wessely, MD, King's
College London, King's Centre for Military Health Research (KCMHR), London, UK;
Paul D. Bliese, PhD, Center for Military Psychiatry and Neuroscience, Walter Reed
Army Institute of Research, US Army Medical Research and Materiel Command, Silver
Spring, Maryland, USA

Correspondence: Nicola T. Fear, King's College London, Academic Centre for Defence Mental Health, Weston Education Centre, 10 Cutcombe Road, London SE5 9RJ, UK. Email: nicola.t.fear@kcl.ac.uk

First received 19 Mar 2013, final revision 24 Jul 2013, accepted 5 Sep 2013

\section{Funding}

J.S., N.T.F., N.G. and S.W. are based at King's College London, which receives funding from the UK Ministry of Defence. US funding for this work comes from the US Army's Military operational Medicine Research Program.

\section{Acknowledgement}

This study was conducted under a cooperative research agreement between King's College London and Walter Reed Army Institute of Research, US Army Medical Research and Materiel Command. We thank Colonel Carl Castro for his vision and support.

\section{References}

1 Fear NT, Jones M, Murphy D, Hull L, Iversen AC, Coker B, et al. What are the consequences of deployment to Iraq and Afghanistan on the mental health of the UK armed forces? A cohort study. Lancet 2010; 375: 1783-97.

2 Hoge CW, Castro CA, Messer SC, McGurk D, Cotting DI, Koffman RL. Combat duty in Iraq and Afghanistan, mental health problems, and barriers to care. N Engl J Med 2004; 351: 13-22.

3 Hoge CW, Terhakopian A, Castro CA, Messer SC, Engel CC. Association of posttraumatic stress disorder with somatic symptoms, health care visits, and absenteeism among Iraq war veterans. Am J Psychiatry 2007; 164: 150-3.

4 Hoge CW, Castro CA. Post-traumatic stress disorder in UK and US forces deployed to Iraq. Lancet 2006; 368: 837.

5 Hotopf M, Hull L, Fear NT, Browne T, Horn O, Iversen A, et al. The health of UK military personnel who deployed to the 2003 Iraq war: a cohort study. Lancet 2006; 367: 1731-41.

6 Sundin J, Fear NT, Iversen A, Rona RJ, Wessely S. PTSD after deployment to Iraq: conflicting rates, conflicting claims. Psychol Med 2010; 40: 367-82.

7 Smith TC, Ryan MAK, Wingard DL, Slymen DJ, Sallis JF, Kritz-Silverstein D. New onset and persistent symptoms of post-traumatic stress disorder self reported after deployment and combat exposures: prospective population based US military cohort study. BMJ 2008; 336: 366-71.

8 Vasterling JJ, Proctor SP, Friedman MJ, Hoge CW, Heeren T, King LA, et al. PTSD symptom increases in Iraq-deployed soldiers: comparison with nondeployed soldiers and associations with baseline symptoms, deployment experiences, and postdeployment stress. J Trauma Stress 2010; 23: 41-51. 
9 Milliken CS, Auchterlonie JL, Hoge CW. Longitudinal assessment of mental health problems among active and reserve component soldiers returning from the Iraq war. JAMA 2007; 298: 2141-8.

10 Thomas J, Wilk J, Riviere L, McGurk D, Castro C, Hoge CW. Prevalence of mental health problems and functional impairment among active component and National Guard soldiers 3 and 12 months following combat in Iraq. Arch Gen Psychiatry 2010; 67: 614-23.

11 Rona RJ, Hooper R, Jones M, Hull L, Browne T, Horn O, et al. Mental health screening in armed forces before the Iraq war and prevention of subsequent psychological morbidity: follow-up study. BMJ 2006; 333: 991.

12 Mulligan $\mathrm{K}$, Fear NT, Jones $\mathrm{N}$, Alvarez $\mathrm{H}$, Hull L, Naumann $\mathrm{U}$, et al. Postdeployment Battlemind training for the U.K. armed forces: a cluster randomized controlled trial. J Consult Clin Psychol 2012; 80: 331-41.

13 Jacobson IG, Ryan MA, Hooper TI, Smith TC, Amoroso PJ, Boyko EJ, et al. Alcohol use and alcohol-related problems before and after military combat deployment. JAMA 2008; 300: 663-75.

14 Browne T, Iversen A, Hull L, Workman L, Barker C, Horn O, et al. How do experiences in Iraq affect alcohol use amongst male UK armed forces personnel? Occup Environ Med 2008; 65: 628-33.

15 McDevitt-Murphy ME, Williams JL, Bracken KL, Fields JA, Monahan CJ, Murphy JG. PTSD symptoms, hazardous drinking, and health functioning among U.S.OEF and OIF veterans presenting to primary care. J Trauma Stress 2010; 23: 108-11.

16 Wilk JE, Bliese PD, Kim PY, Thomas JL, McGurk D, Hoge CW. Relationship of combat experiences to alcohol misuse among U.S. soldiers returning from the Iraq war. Drug Alcohol Depend 2010; 108: 115-21.

17 Fear NT, Iversen A, Meltzer H, Workman L, Hull L, Greenberg N, et al. Patterns of drinking in the UK armed forces. Addiction 2007; 102: 1749-59.

18 Duma SJ, Reger MA, Canning SS, McNeil JD, Gahm GA. Longitudinal mental health screening results among postdeployed U.S. soldiers preparing to deploy again. J Trauma Stress 2010; 23: 52-8.

19 Burnett-Zeigler I, Ilgen M, Valenstein M, Zivin K, Gorman L, Blow A, et al. Prevalence and correlates of alcohol misuse among returning Afghanistan and Iraq veterans. Addict Behav 2011; 36: 801-6.

20 Skopp NA, Reger MA, Reger GM, Mishkind MC, Raskind M, Gahm GA. The role of intimate relationships, appraisals of military service, and gender on the development of posttraumatic stress symptoms following Iraq deployment. J Trauma Stress 2011; 24: 277-86.

21 Meis LA, Barry RA, Kehle SM, Erbes CR, Polusny MA. Relationship adjustment, PTSD symptoms, and treatment utilization among coupled National Guard soldiers deployed to Iraq. J Fam Psychol 2010; 24: 560-7.

22 MacManus D, Dean K, Al Bakir M, Iversen AC, Hull L, Fahy T, et al. Violent behaviour in UK military personnel returning home after deployment. Psychol Med 2011; 42: 1-11.

23 Kok BC, Herrell RK, Thomas JL, Hoge CW. Posttraumatic stress disorder associated with combat service in Iraq or Afghanistan: reconciling prevalence differences between studies. J Nerv Ment Dis 2012; 200: 444-50.

24 Ikin JF, Sim MR, Creamer MC, Forbes AB, McKenzie DP, Kelsall HL, et al. War-related psychological stressors and risk of psychological disorders in Australian veterans of the 1991 Gulf War. Br J Psychiatry 2004; 185: 116-26.

25 Adler AB, Britt TW, Castro CA, McGurk D, Bliese PD. Effect of transition home from combat on risk-taking and health-related behaviors. J Trauma Stress 2011; 24: 381-9.

26 Warner $\mathrm{CH}$, Appenzeller GN, Grieger T, Belenkiy S, Breitbach J, Parker J, et al. Importance of anonymity to encourage honest reporting in mental health screening after combat deployment. Arch Gen Psychiatry 2011; 68: 1065-71.

27 Fear NT, Seddon R, Jones N, Greenberg N, Wessely S. Does anonymity increase the reporting of mental health symptoms? BMC Public Health 2012; 12: 797.

28 Weathers F, Litz B, Herman D, Huska J, Keane T. The PTSD Checklist - Civilian Version (PCL-C). National Centre for PTSD, 1994.

29 Babor TF, Higgins-Biddle JC, Saunders JB, Monteiro MG. AUDIT: The Alcohol Use Disorders Identification Test (2nd edn). World Health Organization, 2001.
30 American Psychiatric Association. Diagnostic and Statistical Manual of Mental Disorders (4th edn) (DSM-IV). APA, 1994.

31 Kroenke K, Spitzer RL, Williams JBW. The PHQ-15: validity of a new measure for evaluating the severity of somatic symptoms. Psychosom Med 2002; 64: 258-66.

32 Unwin C, Blatchley N, Coker W, Ferry S, Hotopf M, Hull L, et al. Health of UK servicemen who served in Persian Gulf War. Lancet 1999; 353: 169-78.

33 Richardson LK, Frueh BC, Acierno R. Prevalence estimates of combat-related post-traumatic stress disorder: critical review. Aust N Z J Psychiatry 2010; 44: 4-19.

34 Wells TS, Miller SC, Adler AB, Engel CC, Smith TC, Fairbank JA. Mental health impact of the Iraq and Afghanistan conflicts: a review of US research, service provision, and programmatic responses. Int Rev Psychiatry 2011; 23: 144-52.

35 Bray RM, Pemberton MR, Lane ME, Hourani LL, Mattiko MJ, Babeu LA. Substance use and mental health trends among U.S. military active duty personnel: key findings from the 2008 DoD Health Behavior Survey. Mil Med 2010; 175: 390-9.

36 Hawkins EJ, Lapham GT, Kivlahan DR, Bradley KA. Recognition and management of alcohol misuse in OEF/OIF and other veterans in the VA: a cross-sectional study. Drug Alcohol Depend 2010; 109: 147-53.

37 Felker B, Hawkins E, Dobie D, Gutierrez J, McFall M. Characteristics of deployed Operation Iraqi Freedom military personnel who seek mental health care. Mil Med 2008; 173: 155-8.

38 Calhoun PS, Elter JR, Jones ER, Kudler H, Straits-Troster K. Hazardous alcohol use and receipt of risk-reduction counseling among U.S. veterans of the wars in Iraq and Afghanistan. J Clin Psychiatry 2008; 69: 1686-93.

39 Bray RM, Pemberton MR, Hourani LL, Witt M, Olmsted KL, Brown JM, et al Department of Defense Survey of Health Related Behaviors Among Active Duty Military Personnel. Defense Technical Information Center, 2009.

40 Ramchand R, Miles J, Schell T, Jaycox L, Marshall GN, Tanielian T. Prevalence and correlates of drinking behaviors among previously deployed military and matched civilian populations. Mil Psychol 2011; 23: 6-21.

41 Wright KM, Foran HM, Wood MD, Eckford RD, McGurk D. Alcohol problems, aggression, and other externalizing behaviors after return from deployment: understanding the role of combat exposure, internalizing symptoms, and social environment. J Clin Psychol 2012; 68: 782-800.

42 Brennen T, Dybdahl R, Kapidzic A. Trauma-related and neutral false memories in war-induced posttraumatic stress disorder. Conscious cogn 2007; 16: 877-85.

43 Koenen KC, Stellman SD, Dohrenwend BP, Sommer Jr JF, Stellman JM. The consistency of combat exposure reporting and course of PTSD in Vietnam War veterans. J Trauma Stress 2007; 20: 3-13.

44 Wessely S, Unwin C, Hotopf M, Hull L, Ismail K, Nicolaou V, et al. Stability of recall of military hazards over time. Evidence from the Persian Gulf War of 1991. Br J Psychiatry 2003; 183: 314-22.

45 Jakupcak $\mathrm{M}$, Conybeare $\mathrm{D}$, Phelps L, Hunt S, Holmes HA, Felker B, et al. Anger, hostility, and aggression among Iraq and Afghanistan war veterans reporting PTSD and subthreshold PTSD. J Trauma Stress 2007; 20: 945-54.

46 Killgore WD, cotting DI, Thomas JL, Cox AL, McGurk D, Vo AH, et al. Post-combat invincibility: violent combat experiences are associated with increased risk-taking propensity following deployment. J Psychiatr Res 2008; 42: 1112-21.

47 Rona RJ, Hooper R, Jones M, Iversen AC, Hull L, Murphy $\mathrm{D}$, et al. The contribution of prior psychological symptoms and combat exposure to post Iraq deployment mental health in the UK military. J Trauma Stress 2009; 22: 11-9.

48 Adler AB, Bliese PD, McGurk D, Hoge CW, Castro CA. Battlemind debriefing and battlemind training as early interventions with soldiers returning from Iraq: randomization by platoon. J Consult Clin Psychol 2009; 77: 928-40.

49 Castro CA, Adler AB, McGurk D, Bliese PD. Mental health training with soldiers four months after returning from Iraq: randomization by platoon. J Trauma Stress; 25: 376-83. 